\title{
Avaliação de um programa para o ensino de leitura e escrita ${ }^{1}$
}

\author{
THAIZE DE SOUZA REIS* \\ DEISY DAS GRAÇAS DE SOUZA** \\ JÚLIO CÉSAR DE ROSE***
}

\begin{abstract}
RESUMO
O presente estudo é parte de uma pesquisa mais ampla, que teve por objetivo avaliar a eficácia de um programa informatizado para o ensino individualizado de leitura e escrita e sua efetividade quando implementado em escolas, pelas próprias professoras. O estudo foi conduzido com 64 alunos que não estavam aprendendo a ler e escrever na sala de aula e que mostraram ausência de leitura em uma avaliação de pré-teste. Foi utilizado um delineamento de grupo em que o Grupo Experimental $(\mathrm{N}=38)$ foi exposto ao programa de ensino de leitura (uma sequência de 17 passos de ensino intercalados com 15 passos de avaliações periódicas), e o Grupo Controle $(\mathrm{N}=26)$ a um programa similar, mas que ensinava somente relações entre palavras ditadas e figuras. Os escores de leitura e de ditado no pós-teste foram acurados e significativamente maiores no Grupo Experimental. Os resultados replicaram e estenderam os resultados de laboratório, o que permite sugerir o emprego do programa de ensino como uma atividade suplementar ao currículo escolar para ensinar alunos que apresentam dificuldades com os procedimentos convencionais de sala de aula.
\end{abstract}

Palavras-chave: Leitura, Escrita, Informática, Processo de ensino-aprendizagem.

\section{RESUMEN}

El presente estudio es parte de una investigación más amplia que tuvo como objetivo evaluar la eficacia de un programa informatizado para la enseñanza individualizada de lectura y escritura y su efectividad al ser implementado en las escuelas por las propias profesoras. El estudio se realizó con 64 alumnos que no estaban aprendiendo a leer y escribir en las clases y que mostraron ausencia de lectura en una evaluación de pre test. Se utilizó un delineamiento de grupo en el que se expuso el Grupo Experimental $(\mathrm{N}=38)$ al programa de enseñanza de lectura (una secuencia de 17 pasos de enseñanza intercalados con 15 pasos de evaluaciones periódicas), y el Grupo Control $(\mathrm{N}=26)$ a un programa similar pero que enseñaba solamente relaciones entre palabras dictadas y figuras. Los resultados de lectura y de dictado en el pos test fueron precisos y significativamente mayores en el Grupo Experimental. Los resultados replicaron y extendieron los resultados de laboratorio, lo que permite sugerir el empleo del

\footnotetext{
${ }^{1}$ Este artigo constitui-se em síntese de uma pesquisa mais ampla (Reis, 2009), que contou com o apoio financeiro da Fundação de Amparo à Pesquisa do Estado de São Paulo (Fapesp).

* Doutoranda do Programa de Pós-Graduação em Psicologia da Universidade Federal de São Carlos/Bolsista Fapesp (thaizereis@gmail.com).

** Professora Titular da Universidade Federal de São Carlos (deisydesouza@gmail.com).

*** Professor Titular da Universidade Federal de São Carlos (juliocderose@ yahoo.com.br).
} 
programa de enseñanza como una actividad suplementaria al currículo escolar para trabajar con alumnos que presentan dificultades con los procedimientos convencionales del aula.

Palabras clave: Lectura, Escritura, Informática, Proceso de enseñanza-aprendizaje.

\begin{abstract}
This study is based on a software designed under the conceptual framework of stimulus equivalence; it is a computerized program for one-on-one teaching of reading and writing focuses on conditional relations between printed words, dictated words and pictures. Additional teaching trials include matching printed syllables to dictated syllables. The assessment of the program in laboratory settings has shown that it is very effective in promoting the emergence of reading and dictation-taking skills. The present study is part of a broader research on the feasibility and efficacy of the teaching program; its specific goal was to evaluate its efficacy when implemented in school settings by the school's staff. Sixty-four students participated. They were not able to learn how to read and write in the classroom and a pre-test evaluation showed hat they did not read single words. The study used a group design. The Experimental Group ( $\mathrm{N}=38$ ) was exposed to the program (a sequence of 17 teaching units interspersed with 15 assessment units). The Control Group ( $\mathrm{N}=26)$ was exposed to a similar program, except that the task just required matching pictures to dictated words and naming the pictures. Reading and writing scores on the post-test were accurate and significantly higher for the Experimental Group. These results replicate and extend the findings of previous studies in laboratory settings, thus recommending the teaching program as a remedial tool that could be useful in supplementing the school efforts to teach students who fail under conventional procedures.
\end{abstract}

Keywords: reading, writing, teaching program, stimulus equivalence. 
Leitura e escrita são habilidades de grande importância para os indivíduos. Dentre os motivos que as tornam tão relevantes, está o fato de permearem a aquisição do conhecimento, além de sua ampla utilização na vida diária (Azevedo; Marques, 2001; Rose, 2005; Ellis, 1995; Morais, 1996). No caso de um estudante em fase de alfabetização, a aprendizagem das habilidades de leitura e escrita adquire importância adicional, pois seu domínio é crucial para o acesso ao conteúdo de outras disciplinas, bem como para sua permanência no processo educacional escolar. Além disso, o domínio do código escrito tem efeitos em outras esferas da vida: indivíduos não alfabetizados ou com pobre desempenho em leitura e escrita podem descrever sentimentos de vergonha ou de inferioridade, e muitas vezes serem estigmatizados na escola ou em seus grupos sociais.

Embora seja direito de todo indivíduo ter acesso a condições de ensino que permitam a aquisição bem-sucedida de leitura e escrita, o sistema educacional brasileiro tem falhado nessa missão. Ainda que aproximadamente $97 \%$ das crianças em idade escolar estejam matriculadas em alguma modalidade de ensino (Brasil, 2002), o que se pode observar é que a escola tem falhado no cumprimento de suas metas (Azevedo; Marques, 2001). Os Parâmetros Curriculares Nacionais (PCNs) sugerem que ao final da $2^{\text {a }}$ série do ensino fundamental os alunos devam ser capazes de compreender o sentido global de textos lidos em voz alta (por eles mesmos ou por outras pessoas), ler de forma independente textos que apresentem conteúdos familiares, escrever utilizando a escrita alfabética, atentando para a segmentação do texto em palavras e frases e para a convenção ortográfica (Cardoso-Martins et al., 2005). No entanto, de acordo com os dados do Instituto Nacional de Estudos e Pesquisas Educacionais Anísio Teixeira (Inep), o desempenho atingido pelos alunos das escolas públicas é inferior ao considerado minimamente satisfatório, pois $55 \%$ das crianças da $4^{\mathrm{a}}$ série avaliadas pelo Sistema Nacional de Avaliação da Educação Básica (Saeb), em 2003, não apresentaram competências e habilidades elementares de leitura (Brasil, 2006) o que, obviamente, não permite que elas dominem as habilidades sugeridas pelos PCNs.

$\mathrm{O}$ alto índice de alunos que apresentam dificuldades na aprendizagem de leitura e escrita é, sem dúvida, uma evidência de que os métodos empregados pelas escolas brasileiras 
não têm sido eficazes (Cardoso-Martins et al., 2005; Capovilla; Capovilla, 2004). No entanto, não se pode deixar de considerar a complexidade do que se pretende ensinar. Para um leitor proficiente, ler e escrever podem parecer tarefas bastante triviais; todavia, exigem do aprendiz uma série de habilidades bastante sofisticadas.

Para ler e escrever o indivíduo deve aprender a relacionar eventos arbitrários (palavras faladas e palavras impressas) a eventos do mundo (figuras, objetos, ações, etc.). As palavras impressas são símbolos para o som das palavras faladas. Estas, por sua vez, são símbolos para os objetos ou eventos do mundo. Entende-se por arbitrariedade a falta de relação natural entre os eventos e a maneira como são denominados. Não há nada, por exemplo, em uma casa que indique seu nome e por isso ela recebe denominações diferentes em diversos idiomas. Dominar essas relações arbitrárias requer uma série de habilidades, como discriminar e manipular os segmentos da fala, discriminar letras individuais, compreender que cada palavra representa uma sequência de sons (fonemas), ter conhecimento de que as letras representam os sons, dominar as representações gráficas correspondentes aos sons da fala, estar familiarizado com textos impressos (crucial para saber em que direção a leitura e a escrita devem ocorrer), entre outras (Cardoso-Martins et al., 2005).

Leitura e escrita, embora interligadas no caso de um leitor proficiente, são dois repertórios inicialmente distintos e que envolvem uma série de relações diferentes. Isso significa que um aluno em fase de alfabetização não é necessariamente capaz de ler uma palavra ao ter aprendido a escrevê-la, assim como pode não ser capaz de escrever uma palavra que tenha aprendido a ler (Rose, 2005; Souza; Rose, 2006; Ellis, 1995). Os aspectos para os quais o aluno deve atentar e a resposta a ser emitida são diferentes em cada caso. Ao ler, o aspecto relevante é o material gráfico e a resposta geralmente é vocal (embora ela também possa ser subvocal, como na leitura silenciosa; tátil, como no Braille; ou gestual, como na linguagem de sinais) (Rose, 2005). Com referência a aspectos importantes do ambiente podem envolver uma palavra ditada ou material gráfico que possa ser copiado. A resposta, no caso da escrita com letra cursiva, envolve produzir a sequência de movimentos que resultam na grafia correta das letras (Ellis, 1995).

Por se tratar de tarefas bastante complexas, uma constatação a que se chega é que nenhum método de ensino, por melhor que seja, é igualmente eficiente com todos os aprendizes (Azevedo; Marques, 2001; Souza; Rose, 2006), o que implica a necessidade 
contínua de desenvolvimento de recursos instrucionais para aqueles que têm mais dificuldades. Como a maioria dos estudantes das escolas públicas brasileiras apresentam desempenhos muito baixos e de forma alguma aceitáveis, métodos de ensino remediativos ou suplementares vêm sendo constantemente investigados por pedagogos, psicólogos e demais pesquisadores da área educacional (Azevedo; Marques, 2001).

Investigações experimentais tendo por objetivo elaborar procedimentos eficazes para o ensino de leitura e escrita a participantes com dificuldades têm sido realizadas por Rose e colaboradores e deram origem a um programa individualizado para o ensino dessas habilidades (Rose et al., 1989; Rose; Souza; Hanna, 1996). Este vem sendo sistematicamente avaliado e aperfeiçoado (Souza; Rose, 2006). A versão original, aplicada com materiais convencionais, deu origem a uma versão informatizada (Rosa Filho et al., 1998), que garante aplicação padronizada a todos os aprendizes e tem se mostrado igualmente eficaz em estudos de laboratório (Souza et al., 2003; Souza; Rose, 2006; Ynoguti, 2002).

Denominado Aprendendo a ler e a escrever em pequenos passos, o programa tem como objetivo auxiliar pessoas (principalmente crianças em fase de alfabetização) que apresentam dificuldades em aprender a ler e a escrever com outros métodos. Para atingir este objetivo, o programa apresenta algumas características especialmente planejadas para lidar com as referidas dificuldades. A primeira característica diz respeito ao fato de o programa ser individualizado, o que permite que cada aluno realize as atividades de ensino de acordo com seu próprio ritmo. Outra característica é a divisão dos repertórios a serem ensinados em pequenas unidades. $\mathrm{O}$ aprendiz pode repetir as unidades de ensino caso não tenha atingido o critério de aprendizagem previamente estabelecido, o que assegura que o progresso ao longo do programa só ocorrerá depois da aquisição dos repertórios previamente ensinados. Além disso, há a revisão constante do que já foi ensinado e a possibilidade de retreino, caso o desempenho não se mantenha. O erro, em programas de ensino desse tipo, é visto como induzido ou fornecido pelo procedimento e serve como base para sua revisão. Assim, os procedimentos são elaborados de forma a permitir que o aprendiz possa sempre atingir o desempenho correto (Rose, 1999). Adicionalmente, evita-se enfatizar o erro do aluno, como é comum em alguns métodos de ensino. Isso acontece com a programação de consequências diferenciais para o desempenho. Quando o aluno apresenta uma resposta correta, recebe uma consequência que é ao mesmo tempo feedback sobre seu desempenho e o encorajamento para 
prosseguir. Quando erra, é informado de que sua resposta está incorreta e tem a oportunidade de responder novamente. O programa de ensino, portanto, é produto de um arranjo de contingências para promover a aprendizagem.

O programa ensina relações entre palavras impressas, figuras e palavras ditadas por meio de um procedimento de emparelhamento com o modelo. Neste procedimento, amplamente utilizado em estudos sobre aprendizagem, o aluno deve escolher entre duas ou mais alternativas (por exemplo, apontar uma figura entre outras duas, circular, sublinhar ou apontar uma entre duas palavras impressas). A base para a escolha correta é um outro elemento (tecnicamente denominado estímulo modelo, estímulo condicional ou estímulo de referência). Por exemplo, o professor pode dizer ao aluno que identifique qual, entre três palavras escritas na lousa, é a palavra bola. A palavra falada pelo professor ("bola") é a referência com base na qual o aluno deve escolher a palavra escrita. Em outro momento, com as mesmas palavras na lousa, o professor pode dizer ao aluno que aponte "carro"; mudando a referência, a escolha deve recair sobre outra palavra escrita. Uma implicação importante do procedimento de emparelhamento com o modelo é que ele favorece a aprendizagem da relação entre cada elemento de referência e o elemento de escolha correspondente. Portanto, quando os modelos são palavras ditadas e os eventos para seleção são palavras escritas ou figuras, o aluno pode aprender relações arbitrárias entre eles. $\mathrm{O}$ mesmo pode ocorrer se o estímulo de referência for uma palavra impressa e os eventos de escolha forem figuras. Além disso, outras aprendizagens são favorecidas. Estudos mostram que os alunos também aprendem sistematicamente a nomear os eventos que escolheram na tarefa de emparelhamento com o modelo (Ferrari; Rose; McIlvane, 1993). Isso demonstra que o emparelhamento entre palavras ditadas e palavras impressas pode ensinar o aluno a dizer qual é a palavra impressa quando ela é apresentada sozinha.

Outro procedimento empregado no programa de ensino é o de exclusão (Dixon, 1977; Ferrari; Rose; Mcllvane, 1993), no qual eventos de escolha conhecidos (previamente relacionados a estímulos de referência) são apresentados simultaneamente com um evento novo. Assim, quando um evento de escolha desconhecido é apresentado, os participantes podem, por exclusão dos eventos já conhecidos, selecionar o evento correto, no caso, o desconhecido. Por exemplo, se a matriz de escolha apresenta as palavras escola e parque, mesmo que o aluno não leia parque, ele pode reconhecer a palavra por exclusão da palavra 
escola, que ele já reconhece diretamente. O reconhecimento é uma importante etapa, uma vez que o aluno pode, no decorrer de uma série de tentativas, ir aprendendo relações de correspondência ponto a ponto entre os sons de parque e os sinais gráficos da mesma palavra. Esse procedimento é relevante, pois permite uma aprendizagem com uma quantidade mínima de erros. A garantia de aprendizagem com essa característica é uma condição importante quando o repertório do aprendiz é muito pobre (Stoddard; Rose; McIlvane, 1986). No caso de crianças com dificuldades, a aprendizagem com um mínimo de erros torna-se ainda mais importante, não só porque elas apresentam uma história de fracasso, mas principalmente porque permite demonstrar a esses alunos que eles são capazes de aprender (Rose, 2005).

O programa também emprega como procedimento de ensino o emparelhamento com o modelo, mas envolvendo a construção da resposta, o CRMTS (constructed-response matching-to-sample). Tarefas que empregam esse procedimento apresentam um estímulo modelo que pode ser visual (figura ou palavra impressa) ou auditivo (palavra ditada), além de apresentarem estímulos para a escolha (letras ou sílabas). A tarefa consiste em selecionar, na ordem correta, as letras ou sílabas disponibilizadas para construir uma palavra correspondente ao modelo apresentado. Quando o modelo é uma palavra impressa, essa tarefa também é denominada cópia. Se o modelo for uma figura, a tarefa pode ser considerada um tipo de ditado mudo, uma vez que a criança deve previamente saber o nome da figura para então construir a palavra correta. Já se o modelo for uma palavra ditada, a tarefa será denominada ditado.

As tarefas ensinadas durante o programa são de dois tipos. Em uma delas, uma palavra ou uma sílaba é ditada ao aprendiz e este deve selecionar a palavra ou sílaba impressa correspondente àquela que foi ditada (tarefa envolvendo emparelhamento com o modelo). A outra tarefa envolve cópia com a construção da resposta (CRMTS). Nesta tarefa, uma palavra impressa é apresentada como modelo, e letras ou sílabas são dispostas na tela do microcomputador. O aluno deve copiar a palavra selecionando, na ordem, as letras ou sílabas de acordo com o modelo apresentado. Essa modalidade de cópia tem por objetivo chamar a atenção do aprendiz para o fato de que palavras são compostas por unidades menores, as sílabas e letras, as quais podem ser recombinadas para a formação de diversas outras palavras. O desenvolvimento da habilidade de recombinação (ler ou escrever palavras que não foram diretamente ensinadas, mas que são compostas por letras ou sílabas de palavras que foram 
ensinadas) é um dos objetivos do programa, pois o número total de palavras ensinadas (51) é relativamente pequeno, se considerarmos as necessidades de um leitor fluente (Rose, 1999). Para avaliar se o programa favorece a recombinação, são apresentados ao aprendiz dois conjuntos de palavras. O Conjunto 1 é composto por palavras que são diretamente ensinadas ao longo de pequenas unidades ou passos por meio dos quais o programa é estruturado. $\mathrm{O}$ Conjunto 2 é constituído por palavras que são apresentadas apenas em tarefas de avaliação. Estas são compostas por recombinação das sílabas que formam as palavras do primeiro conjunto e são apresentadas para verificar se ocorre a abstração das sílabas e a generalização para a leitura de palavras novas.

Os resultados das avaliações têm mostrado, sistematicamente, que ao aprender as tarefas de emparelhamento (tanto de palavras, quanto de sílabas) e de cópia, os alunos passam a ser capazes de nomear as palavras impressas (as mesmas que aprenderam a relacionar com as palavras ditadas), bem como tornam-se capazes de relacionar o mesmo conjunto de palavras impressas às figuras correspondentes e vice-versa. As relações aprendidas consistem nas habilidades componentes da leitura: a identificação ou o reconhecimento de palavras e a compreensão do que foi lido (Cardoso-Martins et al., 2005; Souza; Rose; Domeniconi, 2009; Snow; Griffin; Burns, 2005). Por isso, considera-se que quando o aprendiz demonstra tais relações ele está lendo. Os resultados de estudos prévios mostram que os participantes também desenvolvem a habilidade de escrita. Embora só a cópia esteja envolvida nas tarefas de ensino, a escrita de palavras ditadas também melhora substancialmente como mais um subproduto desejável das condições de ensino (Rose; Souza; Hanna, 1996).

Desde sua primeira versão (Rose et al., 1989), pesquisas vêm sendo realizadas com o intuito de investigar a efetividade desse programa de ensino (Rose et al., 1992; Rose; Souza; Hanna, 1996, Souza et al., 2003, 2004; Hanna et al., 2004; Melchiori; Souza; Rose, 1992; 2000; Ynoguti, 2002). Essas pesquisas, que envolveram diferentes populações (crianças com dificuldades em aprender a ler e a escrever apenas em exposição ao ensino convencional, adultos analfabetos e pessoas com atrasos de desenvolvimento), mostraram que os participantes aprenderam as tarefas de emparelhamento ensinadas no decorrer do programa com bastante precisão, e que a maioria dos alunos passaram de repertórios nulos ou muito baixos em leitura para $100 \%$ de acertos nas avaliações de pós-teste das palavras que são ensinadas. Além disso, os alunos também passaram a ler uma parcela considerável das 
palavras novas (não ensinadas) que contêm recombinações das sílabas das palavras ensinadas. Este é um resultado promissor, que aponta para a possibilidade de que o aluno mostre o desempenho generalizado que é esperado de um leitor proficiente. Os desempenhos em escrita, embora menores quando comparados aos observados em leitura, também aumentaram consideravelmente em ambos os tipos de palavras; isto é, em situação de ditado, não só a porcentagem de acertos das palavras que os alunos aprenderam a emparelhar melhorou, mas também a escrita de palavras novas, embora em porcentagens mais baixas.

Diante dos resultados positivos que vêm sendo obtidos a partir da aplicação do programa de ensino em situação controlada de laboratório, e considerando que este se encontra largamente fundamentado em dados de pesquisa, tornou-se imperioso perguntar sobre sua aplicabilidade em escala mais ampla, na própria escola, conduzida por professores e não mais por pesquisadores.

Complementar uma pesquisa de avaliação dessa amplitude poderia encontrar muitos obstáculos no sistema regular de ensino. No entanto, uma oportunidade propícia surgiu quando a prefeitura de um município de pequeno porte no interior do Estado de São Paulo solicitou a colaboração da universidade para enfrentar as dificuldades de aprendizagem de leitura dos alunos das escolas municipais. Negociações com a prefeitura possibilitaram que o programa informatizado de ensino fosse disponibilizado para todas as escolas do município sob a supervisão de pesquisadores. A prefeitura contratou professores para a aplicação das sessões de ensino e permitiu a condução da pesquisa de avaliação. No âmbito desse acordo, o presente estudo teve como objetivo avaliar a eficiência do programa de ensino quando aplicado em escolas, pelos próprios professores.

\section{MÉTODO}

\section{Situação experimental}

O currículo de ensino de leitura e escrita, desenvolvido por Rose e outros (1989), na versão informatizada, foi implementado em todas as escolas municipais de ensino 
fundamental de uma cidade de pequeno porte no interior do Estado de São Paulo ${ }^{2}$. O programa de ensino foi introduzido nas escolas como atividade suplementar, realizada no contraturno das aulas regulares. Os alunos foram convocados pela Secretaria de Educação do município (por meio das coordenadoras pedagógicas de cada escola) a comparecer às sessões que eram realizadas diariamente na própria escola que frequentavam. Os pais ou responsáveis foram informados sobre as atividades por meio de uma carta, que deveria ser assinada e devolvida à escola para que as atividades tivessem início. O projeto foi aprovado pelo Comitê de Ética em Pesquisa da Universidade Federal de São Carlos (Parecer n ${ }^{\circ}$ 251/2006).

As sessões de ensino eram realizadas individualmente, tinham a duração de aproximadamente 30 minutos e eram aplicadas por professoras da rede municipal. As professoras contratadas para essa finalidade recebiam treinamento e supervisão de membros do grupo de pesquisa responsável pelo desenvolvimento do programa de ensino. Como o programa é informatizado, o treinamento consistiu apenas em ensinar as rotinas necessárias: desde ligar computadores, selecionar procedimentos até gerenciar a distribuição dos alunos pelas estações de trabalho ${ }^{3}$ e monitorar o andamento das sessões. Em nenhum momento o professor foi levado a adotar concepções de ensino e aprendizagem que fundamentavam a elaboração do programa de ensino.

\section{Participantes $^{4}$}

Participaram do estudo 64 crianças (22 meninas e 42 meninos) de $1^{\mathrm{a}}, 2^{\mathrm{a}}$ e $3^{\mathrm{a}}$ séries do ensino fundamental, com idades variando entre seis e onze anos no início da pesquisa. Todas elas frequentavam uma das três escolas em que o programa de ensino de leitura foi implementado e estavam apresentando dificuldades na aprendizagem de leitura e escrita. Trinta e oito alunos foram designados para o Grupo Experimental e 26 para o Grupo Controle.

\footnotetext{
${ }^{2}$ As três escolas do município, em conjunto, atendem por volta de 1000 alunos, dos quais, aproximadamente, $20 \%$ apresentavam baixos escores em tarefas de leitura e escrita.

${ }^{3}$ Ainda que a aplicação do programa fosse individual, vários alunos realizavam as sessões ao mesmo tempo, de acordo com o número de computadores disponível na sala de informática de cada escola. Para isso, cada aluno usava fone de ouvido para ouvir apenas os estímulos ditados referentes à lição que estava sendo trabalhada.

${ }^{4}$ As atividades suplementares foram realizadas com todos os alunos que apresentaram escores inferiores a $70 \%$ de acertos na avaliação inicial de leitura. Essa avaliação incluía um total de 15 palavras. Portanto, foram atendidos desde alunos sem nenhum repertório de leitura até os que liam palavras isoladas, mas que ainda apresentavam erros e podiam ter essa habilidade aprimorada. No entanto, para este projeto de avaliação, foram selecionados apenas os alunos com escores iguais a $0 \%$ de acertos na avaliação inicial.
} 


\section{Seleção dos participantes}

A etapa inicial da pesquisa de avaliação consistiu em identificar os alunos com dificuldades na aprendizagem de leitura e escrita que poderiam se beneficiar com a exposição ao programa de ensino. Essa identificação foi realizada em duas etapas. Na primeira, foi aplicado um ditado ${ }^{5}$ de dez palavras de sílabas simples do tipo consoante-vogal a todos os alunos de $1^{\mathrm{a}}$ à $4^{\mathrm{a}}$ série. Na segunda, os alunos que atingiram um índice de acertos igual ou inferior a $60 \%$ na tarefa de ditado, foram expostos a uma avaliação, realizada individualmente no computador, para medir seu desempenho em tarefas de seleção e nomeação de palavras impressas e de figuras, ditado e cópia. O ditado e a cópia foram realizados em duas modalidades: com letra cursiva (utilizando papel e lápis) e com a construção da resposta no computador. As palavras avaliadas, compostas por sílabas simples do tipo consoante-vogal, foram divididas em dois conjuntos: as palavras do Conjunto 1 foram retiradas do grupo de palavras ensinadas no decorrer do programa, e as do Conjunto 2 foram incluídas apenas em testes, com a função de avaliar a generalização de leitura (Apêndice A).

Todos os alunos que apresentaram $0 \%$ de acertos na tarefa de leitura foram convidados a participar da pesquisa e divididos, por sorteio, entre os grupos Experimental e Controle.

\section{Delineamento}

Foi empregado um delineamento de grupo, com os grupos Experimental e Controle. Os alunos do Grupo Experimental foram expostos ao programa de ensino de leitura. O Grupo Controle pode ser caracterizado como um grupo de tratamento não específico (Kazdin, 2003), pois seus membros também participaram de atividades com as mesmas características gerais das atividades do Grupo Experimental, isto é, foram igualmente recrutados e expostos a procedimentos individualizados, realizados no computador, sob supervisão de uma professora. A única diferença é que para esses participantes as atividades incluíam apenas a seleção de figuras condicionalmente a palavras ditadas e a nomeação de figuras. Essas tarefas

\footnotetext{
${ }^{5}$ Ainda que o desempenho que se pretendia acessar fosse em leitura, o ditado foi utilizado como forma de avaliação por sua correlação com a leitura e por medida de conveniência, uma vez que essa tarefa pode ser aplicada de forma rápida e em situações coletivas. Esta é uma condição importante se considerarmos que todas as crianças de $1^{\mathrm{a}} \mathrm{à} 4^{\mathrm{a}}$ série foram avaliadas.
} 
podem fortalecer e ampliar o vocabulário dos alunos e, uma vez que requerem compreensão auditiva, podem ensinar a relação entre as palavras e as figuras correspondentes e, consequentemente, a nomeação de figuras.

Esse delineamento permitiu a avaliação da eficiência do programa de ensino por comparação entre o Grupo Experimental e o Grupo Controle. O fato de os dois grupos terem sido expostos a condições semelhantes foi uma tentativa de controlar um possível efeito do atendimento individualizado, pois desempenhos superiores no Grupo Experimental poderiam ser atribuídos ao fato de as crianças desse grupo terem realizado uma tarefa em um contexto diferente ao da sala de aula, tido acesso a computadores, a atenção individualizada e a feedback imediato para cada uma das respostas apresentadas.

\section{EXPOSIÇÃO AO PROCEDIMENTO}

\section{Grupo Experimental}

Imediatamente após a avaliação do repertório inicial, os alunos desse grupo foram expostos ao Módulo 1 do programa de ensino desenvolvido por Rose e colaboradores (1989) ${ }^{6}$, que se destina ao ensino de palavras de duas a três sílabas simples do tipo consoante-vogal. O módulo está organizado em unidades e passos, em um total de 17 passos de ensino (três palavras ensinadas por passo) e 15 de avaliação. Depois de terem completado os passos previstos pelo programa, os participantes passaram novamente pela mesma avaliação a que foram submetidos antes da fase de ensino. Esta segunda aplicação teve o propósito de verificar se ocorreram progressos em leitura e escrita em razão da exposição ao módulo de ensino.

\section{Grupo Controle}

Os alunos desse grupo foram expostos ao programa informatizado e individualizado com tarefas de emparelhamento com o modelo para o ensino de relações entre figuras e palavras ditadas e avaliação da nomeação das figuras. O programa ensina 270 relações ao

\footnotetext{
${ }^{6}$ Descrições mais detalhadas do programa e dos procedimentos de ensino podem ser encontradas em Rose; Souza; Hanna (1996); Souza et al. (2004); Souza; Rose (2006); Souza; Rose; Domeniconi (2009).
} 
longo de 30 passos (nove em cada passo). As palavras empregadas foram selecionadas em Pinheiro (1996) e pertencem a três classes gramaticais: substantivo, adjetivo e verbo. Inicialmente, o aluno é solicitado a nomear as figuras que serão ensinadas no passo. Em seguida, são realizadas nove tentativas de emparelhamento. Em cada tentativa, três figuras são apresentadas simultaneamente, e o participante deve selecionar a figura que ilustra a palavra ditada. Por exemplo, se a palavra ditada for "dançar", o aluno deve selecionar a figura de um casal dançando e rejeitar as outras duas: um homem varrendo e uma pessoa fazendo um furo em uma parede. Um desempenho de $100 \%$ de acertos nessa tarefa é critério para nova apresentação do bloco de nomeação: cada figura é apresentada sozinha, no centro da tela, e o aluno deve dizer o nome correspondente. Se a nomeação das nove figuras estiver correta, o aluno prossegue para o passo seguinte. Caso contrário, outro bloco de seleção é realizado, seguido por um novo teste de nomeação. São realizados, no máximo, três blocos de seleção por passo. Por conveniência de expressão, esse programa será referido como "Programa de ampliação de vocabulário". Ao término do programa, os participantes foram novamente expostos à avaliação inicialmente aplicada para efeito de comparação (com seu próprio desempenho inicial e com o dos participantes do Grupo Experimental).

A atividade de ampliação de vocabulário foi realizada com o Grupo Controle para assegurar aos alunos condições semelhantes às do Grupo Experimental. Além disso, questões éticas também determinaram a exposição do Grupo Controle a um programa de ensino. Como ele não seria exposto imediatamente ao ensino de leitura, julgou-se ético ensinar outra habilidade que fosse útil para o desenvolvimento do repertório acadêmico dos alunos (nesse caso, a linguagem oral, considerada um requisito importante para a aprendizagem da linguagem escrita; cf. Snow; Griffin; Burns, 2005). Além disso, o programa apresenta tarefas de emparelhamento com o modelo, o que exige do aluno que atente para os estímulos exibidos e dê uma resposta ativa de seleção. A atenção é um importante pré-requisito para a aprendizagem de leitura e escrita e, provavelmente, é desenvolvida ou fortalecida pela exposição ao programa de ampliação de vocabulário.

Esse grupo passou a ser exposto ao programa de ensino de leitura depois de completada a coleta com o Grupo Experimental. 


\section{Análise dos resultados}

Os principais dados obtidos referem-se ao desempenho dos grupos nas tarefas de leitura e ditado (tanto com construção da resposta no computador quanto com letra cursiva), antes e depois da exposição aos programas de ensino. Esses dados foram submetidos a análises estatísticas para verificar se as diferenças encontradas entre a avaliação inicial e final, em cada grupo e entre grupos, foram significativas. Para a condução das análises estatísticas, utilizou-se o programa SPSS (Statistical Package for Social Science) 10.0 for Windows, tendo sido realizado o Teste $\mathrm{t}$, que permite comparar diferenças entre as médias de duas condições (Dancey; Reidy, 2006).

\section{RESULTADOS}

Além da média, serão apresentadas a mediana e a moda. A média é um dado importante por se tratar de análise de grupo; no entanto, pode sofrer influência de desempenhos individuais extremos. Informações adicionais podem ser fornecidas pela apresentação da mediana (valor que divide a amostra ao meio, de forma que metade dos participantes se situa abaixo do valor representado por essa medida e a outra metade acima desse valor) e da moda (valor mais frequente na amostra). As análises estatísticas, entretanto, foram conduzidas utilizando apenas a média, pois o teste realizado (Teste t) é específico para a comparação entre médias.

Os resultados apresentados refletem o desempenho dos grupos Experimental e Controle nas tarefas de leitura, ditado com construção da resposta no computador e ditado com letra cursiva, de palavras do Conjunto 1 e do Conjunto 2, na avaliação inicial (pré-teste) e na avaliação final (pós-teste) (Figura 1). 
Figura 1 - Porcentagem média de acertos, nas tarefas de leitura, ditado com construção da resposta no computador e ditado com letra cursiva, dos grupos Experimental e Controle ${ }^{*}$

\section{GRUPO EXPERIMENTAL GRUPO CONTROLE}

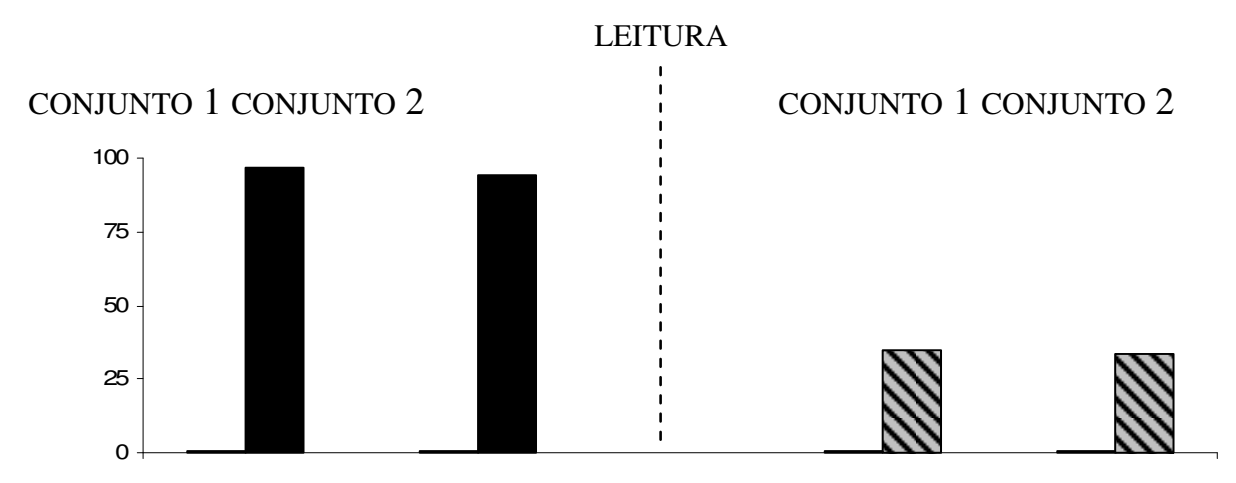

DITADO COM CONSTRUÇÃO DA RESPOSTA NO COMPUTADOR

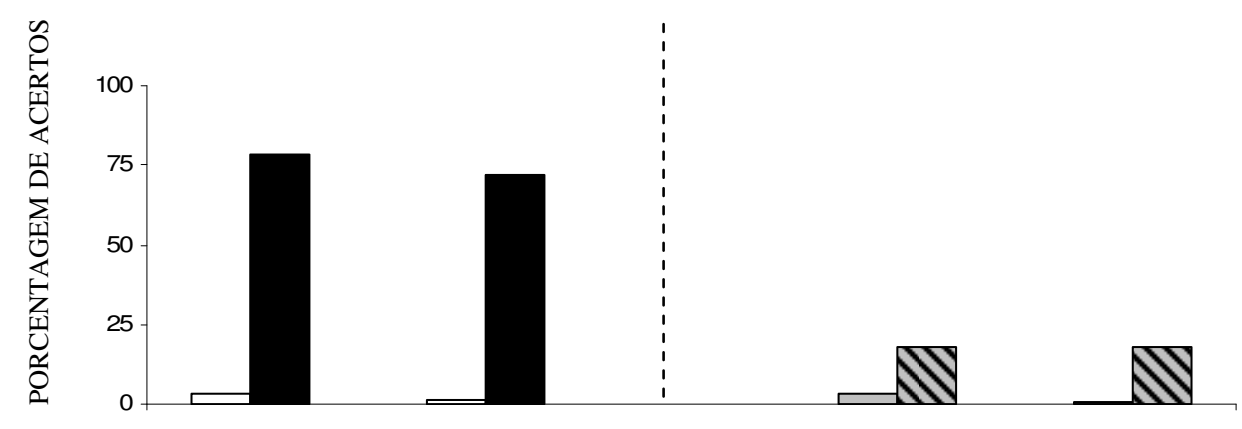

DITADO COM LETRA CURSIVA

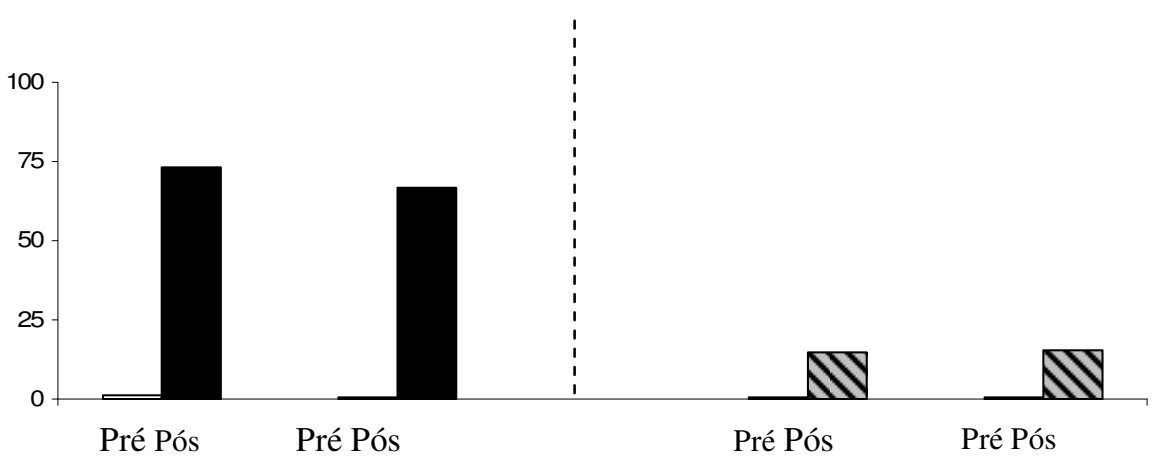

\footnotetext{
* As colunas à esquerda da linha tracejada apresentam o desempenho do Grupo Experimental: as colunas brancas mostram o desempenho no pr tracejada referem-se ao Grupc AVALIAÇÕES , no pós-teste. As colunas à direita da linha o resultado do pré-teste e as hachuradas o resultado do pós-teste. Para os dors grupos, o primeıro par de colunas refere-se ao desempenho com as palavras do Conjunto 1 e o segundo par ao desempenho com as palavras do Conjunto 2.
} 


\section{Leitura}

No pré-teste, ambos os grupos apresentaram $0 \%$ de acertos, tanto com o Conjunto 1 quanto com o Conjunto 2 de palavras, o que configurava o critério de inclusão na pesquisa. Os grupos eram, portanto, equivalentes em relação a essa variável. No pós-teste, o Grupo Experimental leu, em média, 96,8\% das palavras do Conjunto 1 e 94,2\% das palavras do Conjunto 2. O Grupo Controle também apresentou aumento significativo na tarefa de leitura entre o pré e o pós-teste. Essas diferenças observadas entre o pré e o pós-teste foram significativas, de acordo com análises estatísticas conduzidas (Tabela 1).

A porcentagem de acertos com as palavras dos Conjuntos 1 e 2 foi de $35 \%$ e 33,1\%, respectivamente. No entanto, a média final do Grupo Controle, com ambos os tipos de palavra, não reflete o desempenho da maioria dos participantes, pois oito deles ao apresentarem altos desempenhos (alguns acertaram 100\% das palavras do Conjunto 1 e do Conjunto 2) contribuíram para elevar a média do grupo. Por esse motivo, as demais medidas de tendência central são importantes na caracterização do desempenho da amostra. A mediana desse grupo passou de 0 para $10 \%$ de acertos com as palavras do Conjunto 1, e permaneceu inalterada $(0 \%)$ com as palavras do Conjunto 2 . O desempenho mais frequente foi de $0 \%$ de acertos, com os dois conjuntos de palavras, tanto no pré quanto no pós-teste.

O aumento verificado no Grupo Experimental, ao contrário, foi observado em quase todos os participantes. A mediana e a moda desse grupo passaram de $0 \%$ de acertos no préteste para $100 \%$ no pós-teste, com os dois conjuntos de palavras. O desempenho mais baixo na leitura de palavras do Conjunto 1 foi de $70 \%$ de acertos, ao passo que com o Conjunto 2 essa porcentagem foi um pouco menor, $40 \%$, mas muito acima de $0 \%$ obtido no pré-teste. A comparação entre o desempenho do Grupo Experimental e do Grupo Controle permite concluir que as diferenças no pós-teste foram significativas (Tabela 2). 
Tabela 1 - Desempenho médio nas tarefas de leitura, ditado com construção da resposta no computador e ditado com letra cursiva: comparação entre o pré e o pós-teste de cada um dos grupos

\begin{tabular}{|c|c|c|c|c|c|c|c|c|c|}
\hline \multirow{2}{*}{$\begin{array}{l}\text { Tipo de } \\
\text { palavra }\end{array}$} & \multirow[t]{2}{*}{ Medida } & \multicolumn{2}{|c|}{$\begin{array}{c}\text { Experimental } \\
\quad(N=38)\end{array}$} & \multicolumn{2}{|c|}{ Teste $t$} & \multicolumn{2}{|c|}{$\begin{array}{c}\text { Controle } \\
(N=26)\end{array}$} & \multicolumn{2}{|c|}{ Teste $t$} \\
\hline & & $M$ & $D . P$. & $t$ & $g l$ & $M$ & D. $P$. & $t$ & $g l$ \\
\hline \multicolumn{10}{|c|}{ LEITURA } \\
\hline Conjunto 1 & $\begin{array}{l}\text { Pré-teste } \\
\text { Pós-teste }\end{array}$ & $\begin{array}{c}0 \\
96,8\end{array}$ & - & $-85^{* * *}$ & 37 & $\begin{array}{r}0 \\
35\end{array}$ & - & $-4,1^{* * *}$ & 25 \\
\hline Conjunto 2 & $\begin{array}{l}\text { Pré-teste } \\
\text { Pós-teste }\end{array}$ & $\begin{array}{c}0 \\
94,2\end{array}$ & $\begin{array}{c}- \\
13,8\end{array}$ & $-41,8^{* * *}$ & 37 & $\begin{array}{r}0 \\
33\end{array}$ & - & $-3,6^{* *}$ & 25 \\
\hline
\end{tabular}

\section{DITADO COM CONSTRUÇ̃̃O DA RESPOSTA NO COMPUTADOR}

$\begin{array}{llcrlrrrrr}\text { Conjunto } 1 & \text { Pré-teste } & 3,4 & 5,3 & -16,7^{* * *} & 37 & 3,1 & 6,2 & -2,3^{*} & 25 \\ & \text { Pós-teste } & 78,1 & 25,9 & & & 17,7 & 31,3 & & \\ & & & & & & & & & \\ \text { Conjunto 2 } & \begin{array}{l}\text { Pré-teste } \\ \text { Pós-teste }\end{array} & 72,1 & 33 & -12,5^{* * *} & 37 & 0,7 & 3,9 & -2,7^{*} & 25\end{array}$

DITADO COM LETRA CURSIVA

\begin{tabular}{|c|c|c|c|c|c|c|c|c|c|}
\hline Conjunto 1 & $\begin{array}{l}\text { Pré-teste } \\
\text { Pós-teste }\end{array}$ & $\begin{array}{c}1,3 \\
73,1\end{array}$ & $\begin{array}{r}4,1 \\
31,3\end{array}$ & $-14,1^{* * *}$ & 37 & $\begin{array}{l}0,8 \\
15\end{array}$ & $\begin{array}{l}3,9 \\
30,3\end{array}$ & $-2,5^{*}$ & 25 \\
\hline Conjunto 2 & $\begin{array}{l}\text { Pré-teste } \\
\text { Pós-teste }\end{array}$ & $\begin{array}{r}0,5 \\
66,6\end{array}$ & $\begin{array}{r}3,2 \\
36,1\end{array}$ & $-11,1^{* * *}$ & 37 & $\begin{array}{l}0 \\
15,4\end{array}$ & $\begin{array}{l}0 \\
33,6\end{array}$ & $-2,3^{*}$ & 5 \\
\hline
\end{tabular}

$* p<0,05 ; * * p<0,01 ; * * * p<0,001$ 
Tabela 2 - Desempenho médio nas tarefas de leitura, ditado com construção da resposta no computador e ditado com letra cursiva no pré e no pós-teste: comparação entre os grupos Experimental e Controle

\begin{tabular}{|c|c|c|c|c|c|c|c|}
\hline \multirow{2}{*}{ Tipo de palavra } & \multirow{2}{*}{ Medida } & \multicolumn{2}{|c|}{$\begin{array}{l}\text { Experimental } \\
\quad(N=38)\end{array}$} & \multicolumn{2}{|c|}{$\begin{array}{c}\text { Controle } \\
(N=26) \\
\end{array}$} & \multicolumn{2}{|c|}{ Teste $t$} \\
\hline & & $M$ & D. $P$. & $M$ & D. $P$. & $t$ & $g l$ \\
\hline \multicolumn{8}{|c|}{ LEITURA } \\
\hline \multirow{2}{*}{ Conjunto 1} & Pré-teste & 0 & - & 0 & - & - & - \\
\hline & Pós-teste & 96,8 & 7 & 35 & 43,4 & $7,2 * * *$ & 25,8 \\
\hline \multirow{2}{*}{ Conjunto 2} & Pré-teste & 0 & - & 0 & - & - & - \\
\hline & Pós-teste & 94,2 & 13,8 & 33 & 46,3 & $6,5^{* * * *}$ & 28,1 \\
\hline
\end{tabular}

DITADO COM CONSTRUÇÃO DA RESPOSTA NO COMPUTADOR

\begin{tabular}{|c|c|c|c|c|c|c|c|}
\hline \multirow[b]{2}{*}{ Conjunto 1} & Pré-teste & 3,4 & 5,3 & 3 & 6,2 & 0,2 & 62 \\
\hline & Pós-teste & 78,1 & 25,9 & 17,7 & 31,3 & $8,4 * * *$ & 62 \\
\hline \multirow{2}{*}{ Conjunto 2} & Pré-teste & 1 & 4,5 & 0,7 & 3,9 & 0,2 & 62 \\
\hline & Pós-teste & 72,1 & 33 & 17,7 & 33,1 & $6,4 * * *$ & 62 \\
\hline
\end{tabular}

\section{DITADO COM LETRA CURSIVA}

\begin{tabular}{llllllll} 
Conjunto 1 & Pré-teste & \multicolumn{1}{c}{1,3} & 4,1 & 0,7 & 3,9 & 0,5 & 62 \\
& Pós-teste & 73,1 & 31,3 & 15 & 30,3 & $7,3 * * *$ & 62 \\
& & & & & & & \\
Conjunto 2 & Pré-teste & 0,5 & 3,2 & 0 & 0 & 0,8 & 62 \\
& Pós-teste & 66,6 & 36,1 & 15,4 & 33,6 & $5,7 * * *$ & 62 \\
\hline
\end{tabular}

$* * * p<0,001$ 


\section{Ditado com construção da resposta no computador}

Os participantes apresentaram porcentagem baixa de acertos na avaliação inicial: $3,4 \%$ no grupo Experimental e 3,1\% no grupo Controle. Essas diferenças não foram estatisticamente significativas, como mostra a tabela 2. No pós-teste, o índice de acertos no Grupo Experimental com as palavras do Conjunto 1 foi de 78,1\%, e o do Grupo Controle foi de $17,7 \%$. A porcentagem de acertos com as palavras do Conjunto 2 no pós-teste foi de $72,1 \%$ no Grupo Experimental e 17,7\% no Grupo Controle. As diferenças entre o pré e o pós-teste foram significativas para ambos os grupos (Tabela 1). No entanto, também nesta tarefa, desempenhos elevados de alguns participantes contribuíram para aumentar a média de acertos do Grupo Controle. Observando a mediana e a moda, é possível perceber que tais medidas foram de $0 \%$ de acertos no pré e no pós-teste com ambos os conjuntos de palavras. O desempenho mais elevado foi de $100 \%$ de acertos, atingido por um único participante. No Grupo Experimental, a mediana e a moda foram tão elevadas quanto a média. Inicialmente, ambas as medidas foram iguais a zero. No pós-teste, o valor mais frequente foi de $100 \%$, com os dois conjuntos de palavras. A mediana foi de $90 \%$ com as palavras do Conjunto 1 e $80 \%$ com as palavras do Conjunto 2.

Comparando-se o desempenho dos dois grupos, nota-se que no pós-teste houve ganhos observados significativos (Tabela 2).

\section{Ditado com letra cursiva}

Ainda que a análise estatística não tenha mostrado diferenças significativas entre o desempenho inicial dos dois grupos, a média do Grupo Experimental foi ligeiramente superior à do Grupo Controle. O Grupo Experimental acertou, em média, 1,3\% das palavras do Conjunto1 no pré-teste, enquanto o Grupo Controle apresentou 0,8\% de acertos. No pósteste, os índices de acertos dos grupos Experimental e Controle foram 73,1\% e 15\%, respectivamente. Com relação às palavras do Conjunto 2, o Grupo Experimental passou de $0,5 \%$ de acertos no pré-teste para $66,6 \%$ no pós-teste, enquanto o Grupo Controle passou de 0 para $15,4 \%$ de acertos. As diferenças entre o pré e o pós-teste de ambos os grupos foram significativas. Ainda que a diferença entre as médias do Grupo Controle tenha sido expressiva, as demais medidas mostram que o desempenho da maioria dos participantes desse grupo apresentou pequena alteração. A mediana, que foi zero no pré-teste, com 
ambos os conjuntos de palavras, permaneceu inalterada no pós-teste. $\mathrm{O}$ índice de acertos mais frequente, no pré e no pós-teste, com os dois conjuntos de palavras foi $0 \%$. Novamente, os desempenhos elevados atingidos por alguns participantes podem ter contribuído para aumentar a média. Para o Grupo Experimental, a mediana e a moda iniciais também foram nulas: no entanto, no pós-teste essas medidas subiram para 80 e $100 \%$, respectivamente, com os dois conjuntos de palavras. Ainda assim, alguns participantes obtiveram baixas porcentagens de acertos; o menor desempenho apresentado foi de $10 \%$ com as palavras do Conjunto 1 e $0 \%$ com as palavras do Conjunto 2. Observase, portanto, grande variabilidade entre os participantes.

Embora o aumento do Grupo Controle tenha sido significativo, o ganho observado no Grupo Experimental foi superior, tendo as diferenças entre os grupos, depois da exposição ao programa, sido consideráveis, como mostra a Tabela 2.

\section{DISCUSSÃO}

Os resultados do presente estudo mostraram que ambos os grupos obtiveram ganhos, tanto em leitura quanto em escrita, com os dois conjuntos de palavras. As análises estatísticas apontaram ainda que todos os ganhos foram significativos.

Ainda que a melhora do Grupo Controle do pré para o pós-teste também tenha sido expressiva, é possível concluir que o desempenho elevado do Grupo Experimental no pósteste foi resultado do programa de ensino. Essa afirmação se sustenta em alguns pontos: os grupos não diferiam significativamente quanto ao repertório de leitura ou escrita no início da pesquisa; foram expostos a condições experimentais similares, exceto pelo programa de ensino que realizaram; e, adicionalmente, nenhum dos participantes deixou de frequentar a escola durante a realização da pesquisa. A única diferença efetiva entre os grupos foi o programa ao qual foram expostos, o que nos permite concluir que essa variável foi relevante no desempenho posterior observado no Grupo Experimental. $\mathrm{O}$ fato de o Grupo Controle ter apresentado ganhos significativos não prejudica esta conclusão, pois o desempenho do Grupo Experimental no pós-teste foi superior em todas as tarefas, tendo essas diferenças sido significativas. Além disso, era esperado que os alunos apresentassem 
melhoras, uma vez que estavam sendo expostos aos procedimentos de ensino empregados pela escola. Os ganhos, no entanto, não foram observados para todos os participantes do Grupo Controle. Enquanto alguns alunos obtiveram desempenhos perfeitos em leitura e escrita, a maioria não apresentou ganhos ou obteve desempenhos muito baixos. Portanto, a média de acertos do grupo no pós-teste, que não pode ser considerada satisfatória, deveu-se ao desempenho de alguns participantes.

Os resultados deste estudo replicam os dados de pesquisas anteriores que buscaram avaliar a efetividade do programa (Rose et al., 1989; Rose; Souza; Hanna, 1996; Melchiori; Souza; Rose, 1992, 2000; Souza et al., 2004; Ynoguti, 2002).

Em geral, o que todas essas pesquisas apontam é que ao final do módulo de ensino, os participantes passam a ler as palavras do Conjunto 1 com bastante acurácia. A porcentagem de acertos na leitura deste tipo de palavra, na maioria dos estudos, está na faixa entre 67 e 100\% de acertos, embora na última versão avaliada no laboratório os acertos tenham variado entre 90 e 100\% (Souza; Rose, 2006). No presente estudo, a média foi de $96,8 \%$ de acertos. Este valor se encontra na faixa de desempenho dos estudos de laboratório e mostra, portanto, que os alunos aprenderam o repertório alvo.

As pesquisas também têm demonstrado consistentemente que indivíduos expostos ao programa passam a ler as palavras do Conjunto 2, porém os índices são inferiores aos observados com as palavras do Conjunto 1. Verifica-se, ainda, bastante variação nos escores apresentados pelos participantes, sendo que alguns deles atingiam desempenhos comparáveis aos obtidos com as palavras ensinadas, e outros apresentavam desempenhos nulos ou bastante baixos (Rose et al., 1996). Essa variabilidade, porém, foi reduzida com a introdução do emparelhamento entre sílabas ditadas e impressas (Souza; Rose, 2006) e foi replicada neste estudo, que também empregou esse procedimento. No presente estudo, observou-se alguma variabilidade entre os participantes, mas os índices de leitura foram equivalentes com ambos os conjuntos de palavras. Enquanto a mediana de acertos com as palavras do Conjunto 2 nos estudos que não incluíam o emparelhamento entre sílabas era em torno de $40 \%$, com a introdução dessa tarefa ela aumentou para $80 \%$ (Souza; Rose, 2006), tendo chegado a $100 \%$ de acertos no presente estudo. Este índice é superior aos $40 \%$ de acertos das pesquisas anteriores e aos $80 \%$ obtidos com o mesmo procedimento quando aplicado em laboratório, o que permite concluir que o programa além de não perder a 
eficácia, quando aplicado em ambiente escolar, pode até funcionar melhor nessas condições.

Com relação à escrita na tarefa de ditado, as pesquisas mostram que, em geral, os participantes apresentam um aumento em seu desempenho depois da exposição ao programa de ensino, porém os índices são variáveis e bem inferiores aos obtidos em leitura, o que sugere a necessidade de tarefas voltadas especificamente para o ensino de escrita. Sobre o desempenho em escrita, Birnie-Selwyn e Guerin (1997) ressaltam que em programas informatizados para o ensino de leitura erros de escrita geralmente ocorrem, porque não há um ensino específico para desenvolver uma discriminação mais refinada de letras individuais. No estudo de Rose, Souza e Hanna (1996), a média de acertos nesse tipo de tarefa foi de $33,5 \%$. A média de acertos na presente pesquisa foi superior $(78,1 \%)$ com as palavras do Conjunto 1 , o que pode ser efeito do ensino específico da relação entre sílaba ditada e sílaba impressa.

Geralmente, os dados do presente estudo, em consonância com os de trabalhos anteriores, mostraram que a exposição ao programa de ensino proporcionou ganhos elevados na leitura de ambos os tipos de palavras. Os desempenhos em escrita não foram tão elevados quanto os de leitura, mas foram significativamente maiores quando comparados ao repertório inicial dos participantes.

Cabe ressaltar algumas diferenças entre o presente estudo e pesquisas anteriores que empregaram o programa de ensino, no que diz respeito às condições em que as atividades foram realizadas. As pesquisas anteriores foram conduzidas em laboratório, por pesquisadores (ou sob a supervisão constante de um) e com um número relativamente pequeno de participantes. O presente estudo, por sua vez, contou com um número maior de participantes e ocorreu em três escolas diferentes. O contexto de aplicação era diferente não só porque ocorreu em escala mais ampla, mas também em razão das condições em que o programa foi implantado nas escolas. O objetivo principal da implementação não era mais a realização de pesquisas, mas ajudar crianças com dificuldades de aprendizagem a superar a defasagem que apresentavam no repertório de leitura e escrita. A oportunidade de realização de pesquisas, nesse contexto, surgiu com base em negociações com a prefeitura do município. Outro aspecto que diferencia este estudo foi o fato de as sessões de ensino terem sido realizadas por professoras, que, apesar de terem sido treinadas e supervisionadas 
com relativa frequência durante a realização das sessões, não estavam familiarizadas com muitos dos aspectos envolvidos no procedimento. Além disso, os conhecimentos que apresentavam sobre o programa e a abordagem teórica subjacente, muitas vezes, não eram suficientes para que pudessem tomar decisões quando um aprendiz demonstrava muita dificuldade. Obviamente, esses conhecimentos limitados mostravam estreita relação com o treinamento oferecido a essas profissionais. Optou-se por enfatizar os aspectos mais práticos relacionados à aplicação das sessões.

É interessante observar que a despeito de todas essas particularidades, o presente estudo apresenta resultados que replicaram os dados de estudos que utilizaram o programa em outros contextos.

Os progressos obtidos pelos alunos no presente estudo e nas demais pesquisas que empregaram o programa de ensino de leitura é uma evidência de como contingências podem ser adequadamente planejadas para um ensino eficaz. O fato de o programa ser individualizado e permitir que o aprendiz realize as atividades de acordo com seu próprio ritmo, apresentar gradualmente o repertório a ser ensinado, garantir a aprendizagem de um repertório antes de prosseguir para o próximo, proporcionar a oportunidade de revisão do que já foi ensinado, apresentar consequências diferenciais para o desempenho é resultado de um arranjo de contingências que favorecem a aprendizagem das habilidades de leitura e escrita. $\mathrm{O}$ emprego de tais contingências, no entanto, só foi possível graças à realização de pesquisas, o que possibilitou o desenvolvimento de uma literatura pertinente para dar suporte às intervenções.

Recorrer a resultados de pesquisas científicas para embasar as práticas educacionais é algo que o sistema educacional brasileiro deve aprender. Estas medidas costumam ser bem-sucedidas não só em casos de intervenções particulares, tais como as realizadas por grupos de pesquisadores geralmente vinculados a universidades, mas também em contextos mais abrangentes. Países como os EUA, Inglaterra e França, que recorrem a resultados de pesquisas para elaborar suas diretrizes educacionais, conseguiram, fundamentados nessas medidas, reduzir consideravelmente o número de alunos com dificuldades na fase de alfabetização (Cardoso-Martins et al., 2005). A utilização do programa de ensino de leitura pode estar contribuindo, em alguma medida e pelo menos para uma parcela da população, para amenizar as dificuldades na aprendizagem de leitura e escrita, bem como os referidos 
problemas a ela relacionados, pois o programa emprega contingências que até o momento têm resultado na aprendizagem bem-sucedida das habilidades de leitura e escrita. É preciso considerar, no entanto, que nenhum método de ensino é eficaz com todos os aprendizes (Azevedo; Marques, 2001; Souza; Rose, 2006), de forma, que as tarefas apresentadas por esse programa podem não ser suficientes para garantir a aprendizagem de indivíduos que apresentem maiores dificuldades.

Experiências de aplicação do programa em escala mais abrangente, como a relatada em parte neste estudo, representam tentativas de levar os possíveis benefícios de sua utilização a um maior número de pessoas. A ampliação da escala de aplicação deve ser realizada considerando o fato de que o programa foi planejado para funcionar como atividade suplementar e não como um substituto para métodos de alfabetização. Isto pode ser constatado com base na observação do que é efetivamente ensinado. Trata-se de um repertório de leitura, que envolve apenas palavras isoladas compostas por sílabas simples do tipo consoante-vogal. A aprendizagem de um número restrito de palavras não é suficiente para atender as necessidades de um leitor fluente (Rose, 1999). É por esse motivo que o programa apresenta tarefas voltadas para o desenvolvimento da recombinação, pois, dessa forma, o aprendiz é capaz de ampliar o seu repertório, lendo e escrevendo muito mais do que lhe foi ensinado. Não é objetivo do programa (pelo menos, não do Módulo 1 aqui descrito) ensinar leitura de sentenças ou pequenos textos. Ainda que este seja o objetivo final de um ensino bem-sucedido de leitura, um repertório bem estabelecido de leitura de palavras isoladas é a base para leituras mais complexas. Há autores que consideram que ler envolve, antes de qualquer coisa, a capacidade de identificar palavras (Cardoso-Martins et al., 2005). Por esse motivo, o programa adota como objetivo o ensino dessa habilidade mais elementar.

Estes resultados são bastante promissores e permitem vislumbrar a possibilidade de aplicação do programa em escala mais abrangente do que a que vem ocorrendo até o momento. 


\section{REFERÊNCIAS BIBLIOGRÁFICAS}

AZEVEDO, M. A.; MARQUES, M. L. Alfabetização hoje. 4. ed. São Paulo: Cortez, 2001.

BIRNIE-SELWYN, B.; GUERIN, B. Teaching children to spell: decreasing consonant cluster errors by eliminating selective stimulus control. Journal of Applied Behavior Analysis, v. 30, n. 1, p. 69-91, 1997.

BRASIL. Ministério da Educação. Instituto Nacional de Estudos e Pesquisas Educacionais. Geografia da educação brasileira 2001. Brasília: Inep, 2002.

. Relatório Nacional Saeb 2003. Brasília: Inep, 2006.

CAPOVILlA, A. G. S.; CAPOVILlA, F. C. Alfabetização: método fônico. São Paulo: Memnon, 2004.

CARDOSO-MARTINS, C. et al. Os Novos rumos da alfabetização infantil: relatório encomendado pela Câmara dos Deputados ao painel internacional de especialistas em alfabetização infantil. São Paulo: Memnon, 2005.

DANCEY, C. P.; REIDY, J. Estatística sem matemática para psicologia: usando SPSS para Windows. In: Artmed, 2006. p. 219-248.

DIXON, L. S. The Nature of control by spoken words over visual stimulus selection. Journal of the Experimental Analysis of Behavior, v. 27, n. 3, p. 433-442, 1977.

ELLIS, A. W. Leitura, escrita e dislexia. Porto Alegre: Artes Médicas, 1995.

FERRARI, C.; ROSE, J. C. de; MCILVANE, W. J. Exclusion vs. selection training of auditory-visual conditional relations. Journal of Child Psychology, v. 56, p. 49-63, 1993.

HANNA, E. S. et al. Effects of delayed constructed-response identity matching on spelling of dictated words. Journal of Applied Behavior Analysis, v. 37, n. 2, p. 223-227, 2004.

KAZDIN, A. E. Research design in clinical psychology. Boston: Allyn and Baron, 2003.

MELCHIORI, L. E.; SOUZA, D. G. de; ROSE, J. C. C. de. Aprendizagem de leitura por meio de um procedimento de discriminação sem erros (exclusão): uma replicação com préescolares. Psicologia: Teoria e Pesquisa, v. 8, n. 1, p. 101-111, 1992.

Reading, equivalence and recombination of units: a replication with students with different learning histories. Journal of Applied Behavior Analysis, v. 33, p. 97-100, 2000 .

MORAIS, J. A Arte de ler. São Paulo: Universidade Estadual Paulista, 1996. 
PINHEIRO, A. M. V. Contagem de frequência de ocorrência de palavras expostas a crianças na faixa pré-escolar e séries iniciais do $1^{\text {o }}$ grau. 1996. (Software sem registro de patente).

REIS, T. S. Avaliação de um programa suplementar para o ensino de leitura e escrita aplicado em ambiente escolar. 2009. Dissertação (Mestrado em Educação Especial). Universidade Federal de São Carlos, São Carlos.

ROSA FILHO, A. B. et al. Aprendendo a ler e escrever em pequenos passos. 1998. (Software para pesquisa)

ROSE, J. C. de. Análise comportamental da aprendizagem de leitura e escrita. Revista Brasileira de Análise do Comportamento, v. 1, n. 1, p. 29-50, 2005.

Explorando a relação entre ensino eficaz e manutenção da disciplina. In: NUNES SOBRINHO, F. P.; CUNHA, A. C. B. da. Dos problemas disciplinares aos distúrbios de conduta: práticas e reflexões. Rio de Janeiro: Dunya, 1999. p. 1-23.

ROSE, J. C. de; SOUZA, D. G. de; HANNA, E. S. Teaching reading and spelling: exclusion and stimulus equivalence. Journal of Applied Behavior Analysis, v. 29, n. 4, p. 451-469, 1996.

ROSE, J. C. de et al. Aquisição de leitura após história de fracasso escolar: equivalência de estímulos e generalização. Psicologia: teoria e pesquisa, v. 5, p. 325-346, 1989.

Stimulus equivalence and generalization in reading after matching to sample by exclusion. In: HAYES, S. C.; HAYES, L. J. Understanding verbal relations. Reno: Context Press, 1992. p. 69-82.

SNOW, C. E.; GRIFFIN, P.; BURNS, M.S. Knowledge to support the teaching of reading: preparing teachers for a changing world. San Francisco: Jossey-Bass, 2005.

SOUZA, D. G. de; ROSE, J. C. de. Desenvolvendo programas individualizados para o ensino de leitura. Acta Comportamentalia, v. 14, n. 1, p. 77- 114, 2006.

SOUZA, D. G. de; ROSE, J. C. de; DOMENICONI, C. Applying relational operants to reading and spelling. In: REHFELDT, R. A.; BARNES-HOLMES, Y. Derived relational responding: applications for learners with autism and other developmental disabilities. CA (EUA): New Harbinger Publications, 2009. p. 171-207.

SOUZA, D. G. de et al. Análise comportamental da aprendizagem de leitura e escrita e a construção de um currículo suplementar. In: HÜBNER, M. M. C.; MARINOTTI, M. Análise do comportamento para a educação: contribuições recentes. Santo André: Esetec, 2004. p. 177-204. 
Generalização recombinativa na aquisição de leitura. In: REUNIÃO ANUAL DA SOCIEDADE BRASILEIRA DE PSICOLOGIA, 33., 2003, Belo Horizonte. Anais... Ribeirão Preto: Villimpress, 2003. p. 34.

STODDARD, L. T.; ROSE, J. C. C. de; MCILVANE, W. Observações curiosas acerca do desempenho deficiente após a ocorrência de erros. Psicologia, v. 12, n. 1, p. 1-18, 1986.

YNOGUTI, A. E. N. O Uso do computador como instrumento de ensino: analisando sua eficiência no ensino individualizado de leitura. 2002. Dissertação (Mestrado em Educação Especial). Universidade Federal de São Carlos, São Carlos.

Recebido em: julho 2009

Aprovado para publicação em: outubro 2009 
Apêndice A - Palavras ensinadas e testadas pelo programa de ensino de leitura

\begin{tabular}{|c|c|c|}
\hline \multicolumn{3}{|c|}{ PALAVRAS DO PROGRAMA DE ENSINO DE LEITURA } \\
\hline PALAVRA & NSINO DO & PALAVRAS DE GENERALIZAÇÃO \\
\hline \multicolumn{2}{|c|}{ CONJUNTO 1} & DO CONJUNTO 2 \\
\hline ALUNO & REMO & BIGODE \\
\hline APITO & RIO & BOCA \\
\hline $\mathrm{BICO}$ & ROUPA & BONECA \\
\hline BOLO & RUA & CABIDE \\
\hline BULE & SALADA & CAMELO \\
\hline CADEADO & SAPO & CANECA \\
\hline CAFÉ & SELO & COLA \\
\hline CAJU & SINO & FADA \\
\hline CAVALO & SOFÁ & FILA \\
\hline DEDO & SUCO & FUMO \\
\hline FACA & TAPETE & GALO \\
\hline FIGO & TATU & JACA \\
\hline FIVELA & TIJOLO & LATA \\
\hline FOGO & TOMATE & LIMA \\
\hline FUBÁ & TUBO & LOBO \\
\hline GATO & UVA & LOJA \\
\hline GAVETA & VACA & LUPA \\
\hline GOIABA & VELA & MACACO \\
\hline JANELA & VIOLINO & MAPA \\
\hline LUA & VOVÔ & PALITO \\
\hline LUVA & & PIPA \\
\hline MALA & & RATO \\
\hline MENINA & & RODA \\
\hline MOEDA & & SACOLA \\
\hline MULA & & SAPATO \\
\hline MULETA & & SOPA \\
\hline NAVIO & & TOCO \\
\hline PANELA & & TOMADA \\
\hline PATO & & TUBA \\
\hline PETECA & & TULIPA \\
\hline RÁDIO & & VAGALUME \\
\hline
\end{tabular}

